
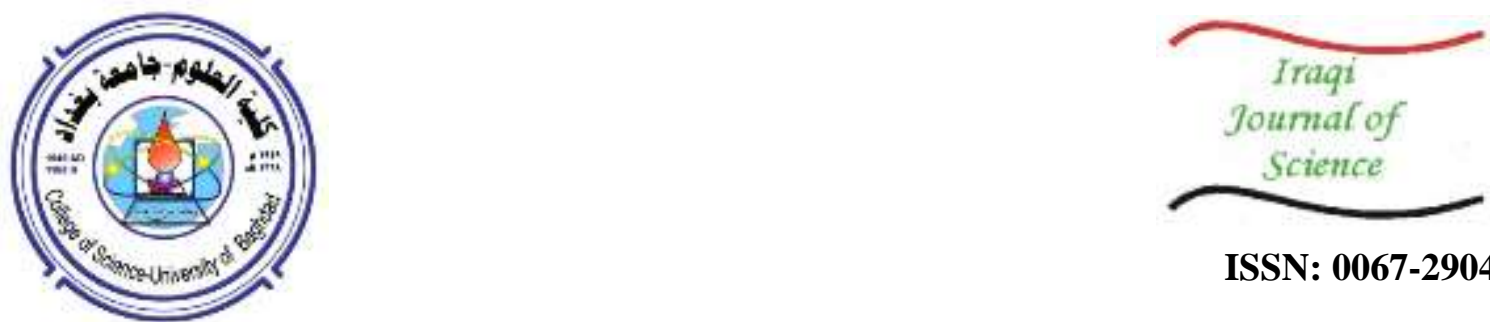

ISSN: 0067-2904

\title{
The Performance of Plasmonic Gold and Silver Nanoparticle-Based SERS Sensors
}

\author{
Alwan M. Alwan, Mohammed S. Mohammed, Russul M. Shehab* \\ Department of Applied Sciences, University of Technology, Baghdad, Iraq
}

\author{
Received: 4/12/ 2019 \\ Accepted: 19/3/2020
}

\begin{abstract}
The influence of different types of plasmonic gold (Au-NPs) and silver (Ag-NPs) nanoparticles as well as aging on the performance of Surface-Enhanced Raman Scattering (SERS) sensors were studied. The average diameters of Au-NPs and AgNPs were about $23 \mathrm{~nm}$ and $15 \mathrm{~nm}$, respectively, with a number of laser pulses of about 200. plasmonic nanoparticles were synthesized by laser ablation process in distilled water using a fixed energy laser fluence of about $14 \mathrm{~J} / \mathrm{cm}^{2}$ of Nd-YAG laser, with $1060 \mathrm{~nm}$ wavelength and $1 \mathrm{~Hz}$ pulse repetition rate. The SERS sensor was carried out by quick drop casting process of plasmonicplasmonic nanoparticles on glass substrates. The morphological aspects and the performance of SERS sensors were investigated by high resolution transmission electron microscopy (HRTEM) and Raman spectroscopy. All the results indicated the significant dependence of the performance of the sensor on the types of the plasmonic nanoparticles. The obtained Raman signal intensity of Ag-NPs was about $10^{5}$ a.u. compared with $10^{3}$ a.u. for Au-NPs. While, the stability of Au-NPs was much higher than that of Ag-NPs based on SERS sensors due to the normal oxidation process of Ag-NPs.
\end{abstract}

Keywords: Plasmonic Nanoparticles, Surface Enhanced Raman Scattering, Laser Ablation.

\section{أداء متحسس حيود رامان المعزز سطحيا بجسيمات الذهب والفضة البلازمونية

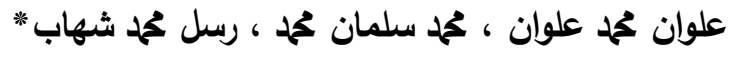

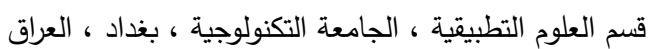

تمت دراسة تأثير أنواع مختلفة من جسيمات النانوية للذهب و جسيمات النانوية للفضة البلازمونية

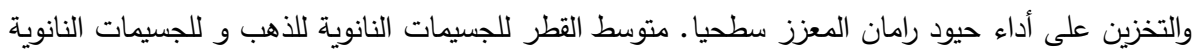

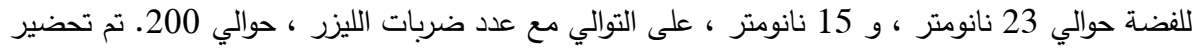

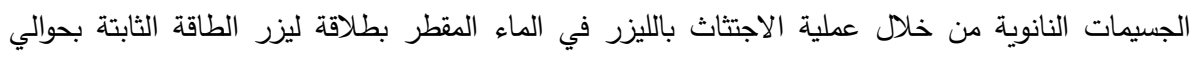

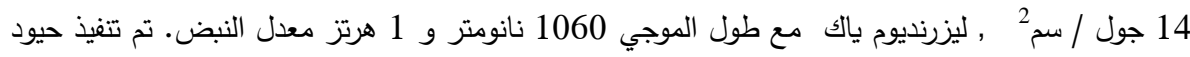

رامان المعزز سطحيا من خلال عملية الصب السريع بالإنساط للجسيمات النانوية البلازمونية على ركائز

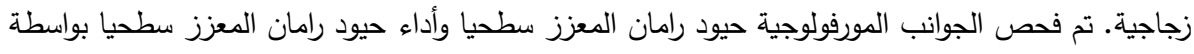

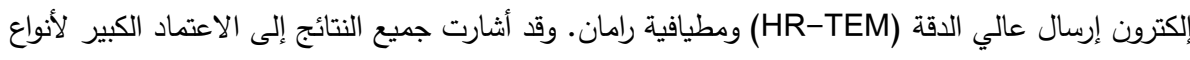

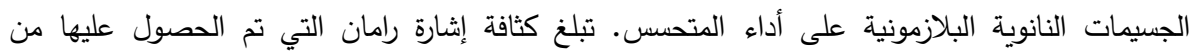

*Email: russullaser@yahoo.com 


$$
\begin{aligned}
& \text { الجسيمات النانوية للفضة حوالي (a.u105.) مقارنة بـ (a.u103.) لـ جسيمات النانوية للذهب. في حين أن } \\
& \text { ثبات جسيمات النانوية للذهب أفضل بكثير من قيمة الجسيمات النانوية للفضة استتادًا إلى حيود رامان المعزز } \\
& \text { سطحيا بسبب عملية الأكسدة العادية للجسيمات النانوية الفضية. }
\end{aligned}
$$

\section{Introduction}

The potential applications of nanostructures in chemical and biochemical sensors as well as industrial and nano photonics fields depend on the dimensions, forms, and physicochemical characteristics of the plasmonic nanomaterials [1-5]. A number of chemical and physical approaches are employed to produce these materials, such as ion reduction process, thermal dissociations of metal salts, electrochemical process, and pulsed laser ablation process $[6,7]$. The latter process is a green, fast, and simple physical technique for the production of colloidal suspensions of metallic plasmonic nanoparticles (gold and silver). Furthermore, the significant advantage of this technique over the other approaches is the formation of high surface-purity nanoparticles without counter ions or residuals of the reducing agents left over on the surfaces of the nanoparticles [8-10]. The surface enhanced Raman scattering (SERS) sensors were prepared via the ion reduction process of silver and gold ions by the dangling bonds of the porous silicon layer and, hence, the fabrication of porous silicon-based SERS sensors [11-13]. Colloidal suspensions of plasmonic nanoparticles were deposited on glass substrates immobilize them and to inspection those for possible request as an active substrate for sensing of Rohdamine 6G (R6G) via glass-based SERS sensors.

The consequences of SERS and hence the improvement of the Raman signal are mainly due to the inelastic scattering of specific target molecules in the presence of plasmonic metallic nanoparticles [13]. The main reason behind this improvement is the energy transfer process among the nanoparticles and the target molecules on the based substrate (porous silicon, rough surface and glass substrate). The rate of the transfer is increased with increasing the density of the plasmonic nanoparticles and hot spot regions [14-19].

The purpose of the present work is to investigate the influence of different types of plasmonic nanoparticles (Au-NPs and Ag-NPs) on the performance of as-prepared and air aged SERS sensors for detecting ultra-low concentrations of R6G molecules, which is a dye cytotoxic to Friend leukemia cells and doxorubicin-resistant variant cells.

\section{Materials and Methods}

Plasmonic nanoparticles (Au-NPs and Ag-NPs) were individually prepared via pulsed laser ablation technique for gold and silver plates (purity of 99.99\%), located in a glass vessel filled with $5 \mathrm{~mL}$ distilled water (DW). Colloidal suspensions of Au-NPs and Ag-NPs were synthesized by laser ablation process using a fixed energy laser fluence of about $14 \mathrm{~J} / \mathrm{cm}^{2}$ of Nd-YAG laser with $1060 \mathrm{~nm}$ wavelength, $1 \mathrm{~Hz}$ pulse repetition rate, and 200 pulses, as shown in Figure-1. Nanoparticle layer of SERS was prepared by drop casting technique of suspensions of Au-NPs and Ag-NPs on a glass slide. A few droplets of an R6G solution of $10^{-10} \mathrm{M}$ concentration were dropped and left to be dried on the SERS substrate to study the performance of as-prepared and air aged SERS sensors after a period of 6 months. To characterize the morphological aspects and the performance of SERS sensors, high resolution transmission electron microscopy (HR-TEM, Philips CM30, USA), Raman microscope, and a UV-Vis beam spectrophotometer (Shemadze, Japan) were employed. Raman bands of R6G dye resulting from Au-NPs/glass and Ag-NPs /glass SERS sensors were recorded via dispersive Raman microscope (Senterra 2009, Bruker, Germany) through $750 \mathrm{~nm}$ excitation wavelength and $50 \mathrm{~mW}$ scanning power, as shown in Figure-2. 


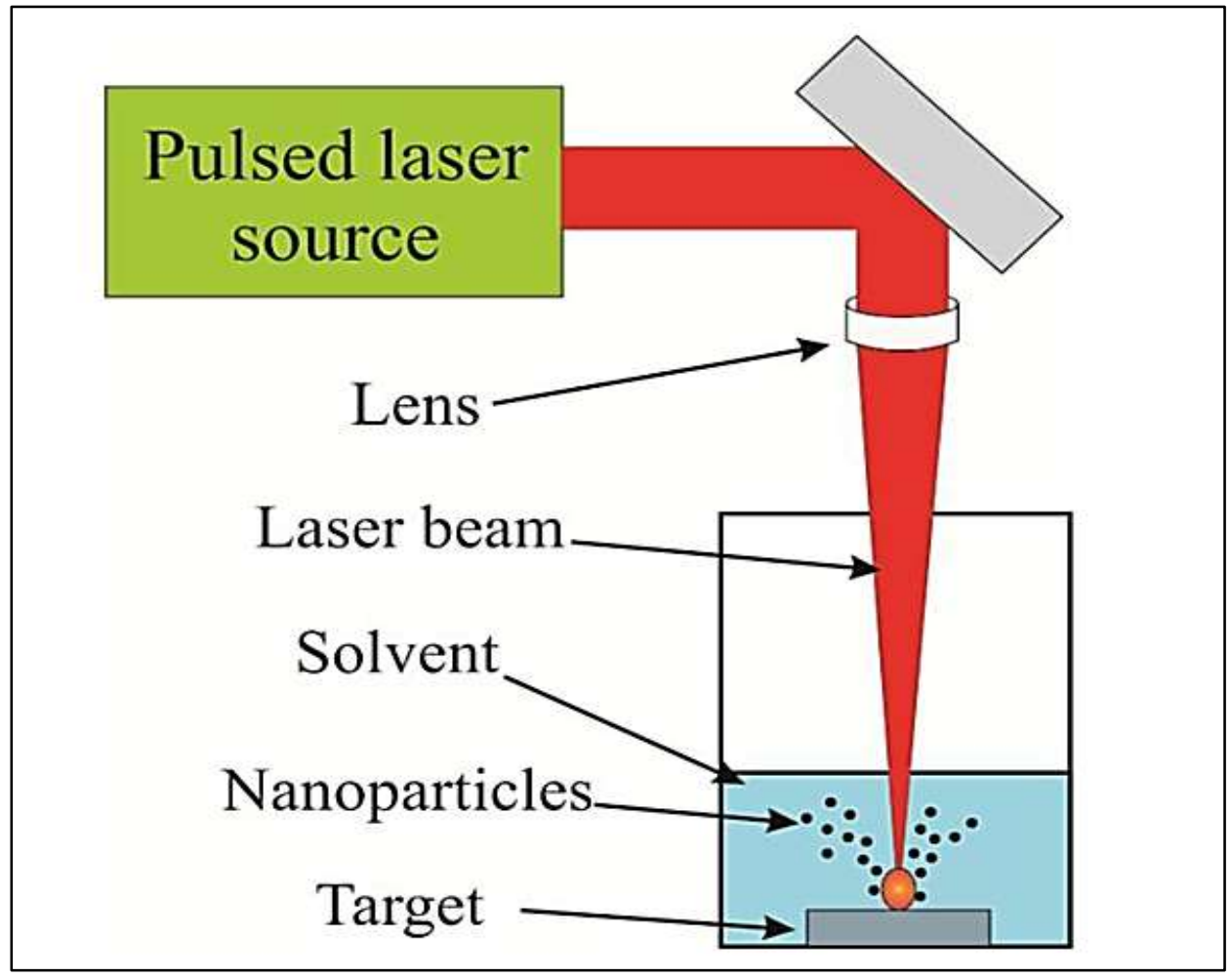

Figure1-Setup of the formation of colloidal suspension nanoparticles by pulse laser ablation in liquid

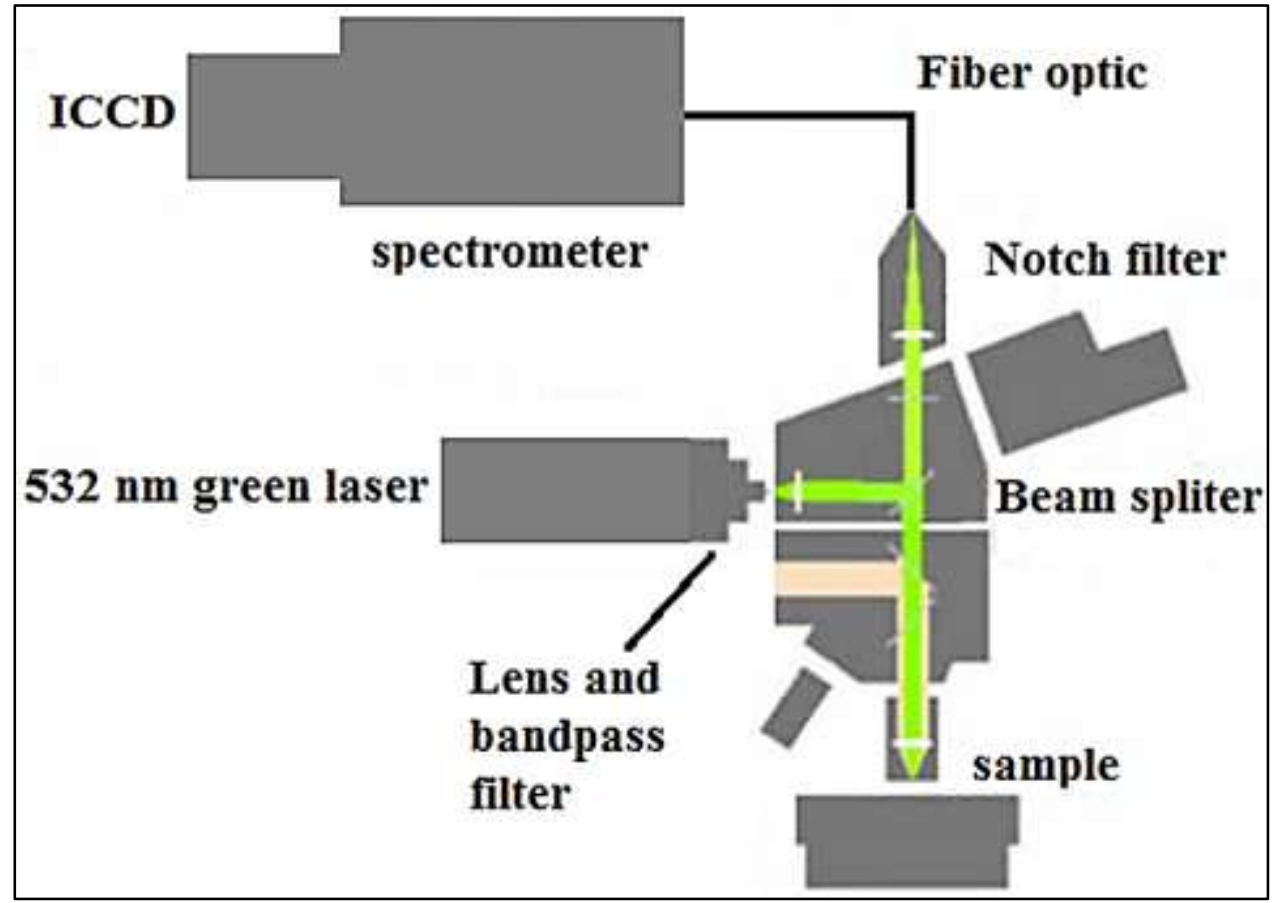

Figure 2-Schematic diagram of the Raman microscope

\section{Results and discussion}

\subsection{Plasmonic features}

The absorption spectra of the colloidal Au-NPs and Ag-NPs are illustrated in Figure-3. The resonance absorption peaks corresponding to the AuNPs and AgNPs were found to be at $525 \mathrm{~nm}$ and $425 \mathrm{~nm}$, respectively. 


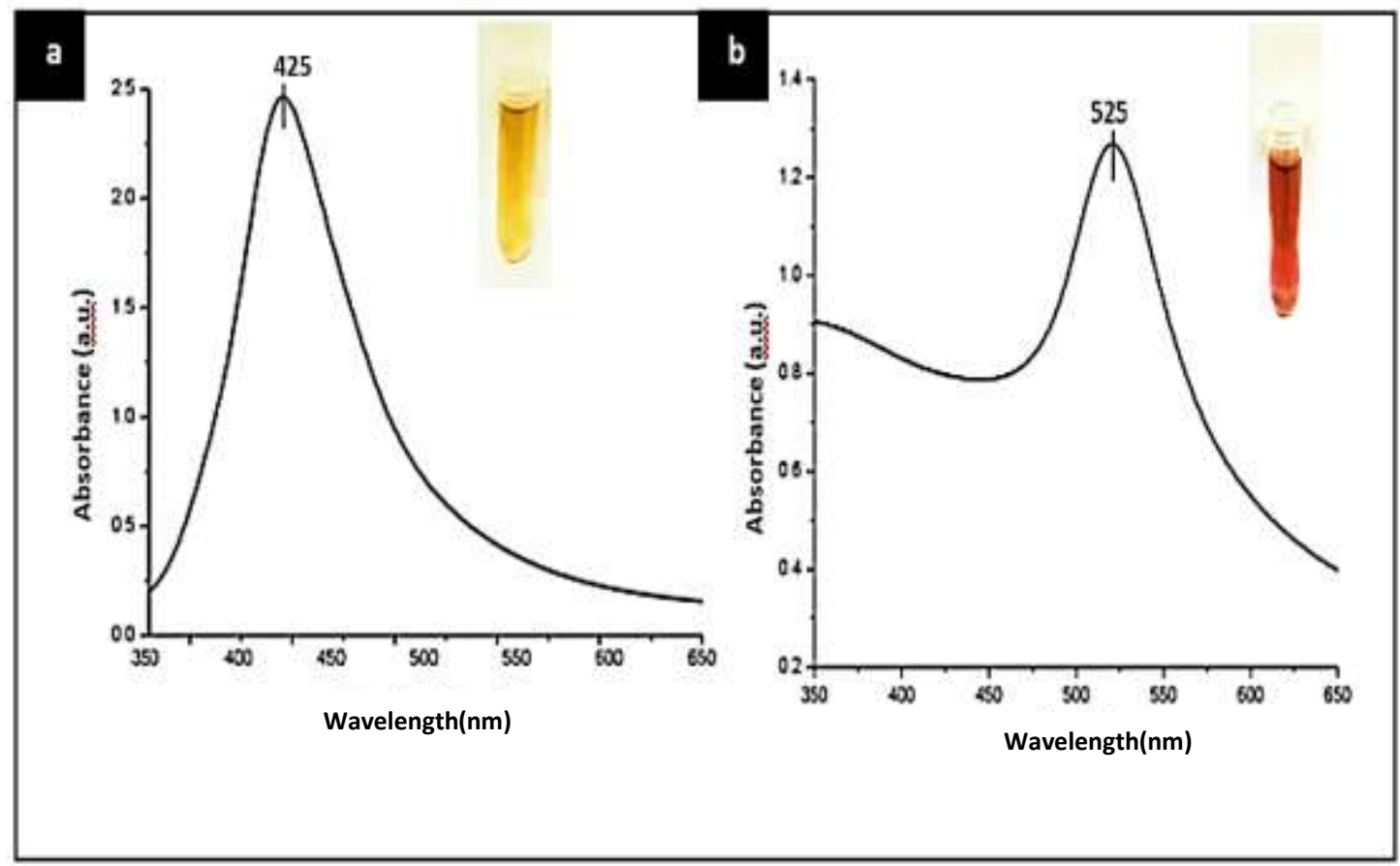

Figure 3-Absorbance spectra of colloids (a) Au-NPs (b) Ag-NPs.

The insets in Figure-3 represent the images of Au-NPs and Ag-NPs colloidal suspensions. The surface morphology of Au-NPs and Ag-NPs deposited on the glass substrate was studied through the analysing of their HR-TEM images shown in Figure-4. From this figure, the form of the deposited plasmonic nanoparticles on the glass substrate appears somewhat spherical in shape. The diameter of the Au-NPs ranged from 100 to $12 \mathrm{~nm}$ with an average value of about $23 \mathrm{~nm}$, whereas the Ag-NPs diameter varied from 90 to $8 \mathrm{~nm}$ with an average value of about $15 \mathrm{~nm}$. The plasmonic particles were of a nano-scale size and the specific surface area was attained with the smaller plasmonic sizes. The average sizes of the plasmonic Au-NPs and Ag-NPs were calculated from the HR-TEM images using special software (ImageJ). [20]:

The specific surface area (S.S.A) of the plasmonic nanoparticles was calculated using equation (1)

$$
\text { S.S. } A=\frac{6 \times 10^{3}}{D_{P^{*} \rho_{A g-A u N P s}}}
$$

where $\mathrm{D}_{\mathrm{p}}$ is the grain size of Ag-AuNPs and $\rho_{\mathrm{Ag}-\mathrm{AuNPs}}$ is the density of the bimetallic alloy of AgAuNPs $\left(\mathrm{g} / \mathrm{cm}^{3}\right)$, which was calculated based on the density of gold and silver independently, as follows.

$$
\rho_{A g-A u N P s}=\frac{a * \rho_{A u}+b * \rho_{A g}}{a+b}
$$

where, a is wt. $\% \mathrm{Au}, \mathrm{b}$ is wt. $\% \mathrm{Ag}, \rho_{\mathrm{Au}}$ is the density of gold, and $\rho_{\mathrm{Ag}}$ is the density of silver. The values of S.S.A of Au-NPs and Ag-NPs were about 20.3 and $30.7 \mathrm{~m}^{2} / \mathrm{gm}$, respectively. The achieved value of S.S.A of Ag-NPs of the as-prepared sample was higher than that of Au-NPs due to the fact that their size is smaller owing to their lower tendency of aggregation [20, 21]. 


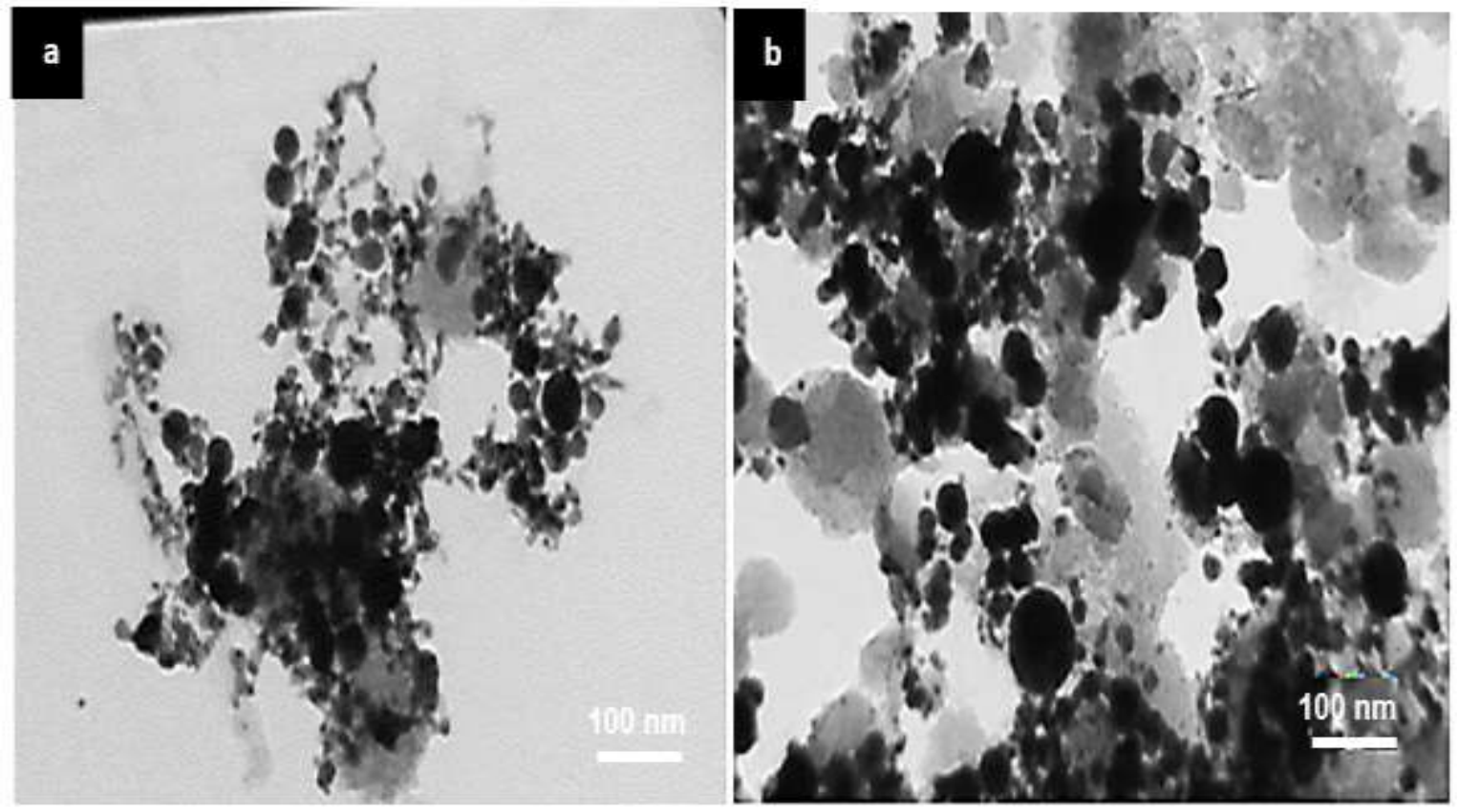

Figure 4-HR-TEM images of colloids (a) Ag-NPs and (b) Au-NPs.

Figure-5 illustrates the results of the energy-dispersive X-ray spectroscopy (EDS) analysis of asprepared Au-NPs and Ag-NPs (a and c) and those after 6 months of air ageing (b and d). These spectra showed definitively that the intensity of Au-NPs does not change with time, while it is clear that the peak for Ag-NPs was decreased with time due to the growth of the oxide layer and, hence, the presence of a new phase of silver nanoparticles in the form of $\mathrm{Ag}_{2} \mathrm{O}$ [22] specific peaks related to the presence of the gold and silver elements in addition to that of oxygen for the case of silver aged sample.
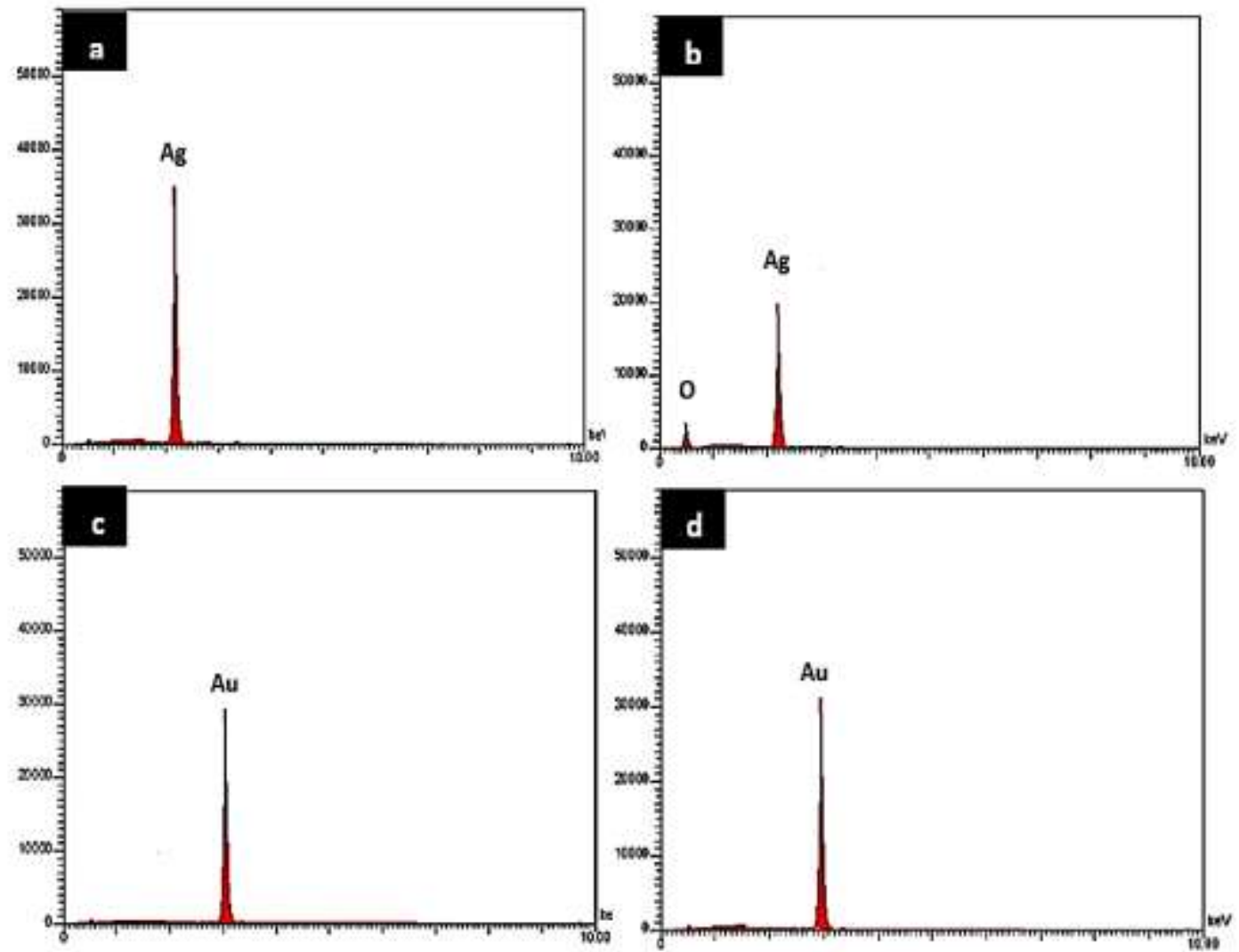

Figure5- EDS analysis of Au-NPs and Ag-NPs: (a and c) as-prepared, (b and d) after 6 months. 


\subsection{Raman spectra of Au-NPs and Ag-NPs /glass SERS sensors}

Raman spectra measurements of Au-NPs and Ag-NPs/glass of SERS sensors, as depicted in Figure- 6, show spectra consisting of five particular Raman peaks of high intestines which signify the R6G and located at 1650, 1574, 1517, 1364 and $1279 \mathrm{~cm}^{-1}$. These particular peaks are intensely coupled to $\mathrm{C}-\mathrm{C}$ and $\mathrm{C}-\mathrm{H}$ bond stretching vibrations [22, 23]. The activities of both as-prepared and air-aged Au-NPs and Ag-NPs/glass SERS sensors for the R6G target molecules, at a low concentration of about $10^{-10}$ M, are shown in Figure-6. For Au-NPs /glass SERS sensors, the obtained Raman intensity of the main peaks at a wave number of about $1650 \mathrm{~cm}-1$ did not change significantly with the aging period, with an intensity value of about $\mathrm{I}_{\mathrm{SERS}}=10^{3}$. While, for Ag-NPs /glass SERS sensors, the intensity of Raman peaks suffered a large degradation in intensity with the aging period by a factor of two order of magnitudes. This degradation in intensity is strongly related to the decrease in the density of hot spot regions with the aging time [11]. Also, the growth of the oxide layer leads to an increase in the size of the plasmonic nanoparticles and, hence, a decreased activity of the local antenna (plasmonic nanoparticles) [12]. The intensity of Raman signal resulting from as-prepared Au-NPs and Ag-NPs /glass SERS sensors was much higher than that of Au-NPs/glass SERS sensor. This performance is related to the exposure area (interaction volume), where the increasing of the S.S.A in the case of AgNPs will increase the probability of energy transfer among the plasmonic nanoparticles and the target molecules and, hence, increase the Raman signal [20,22] .

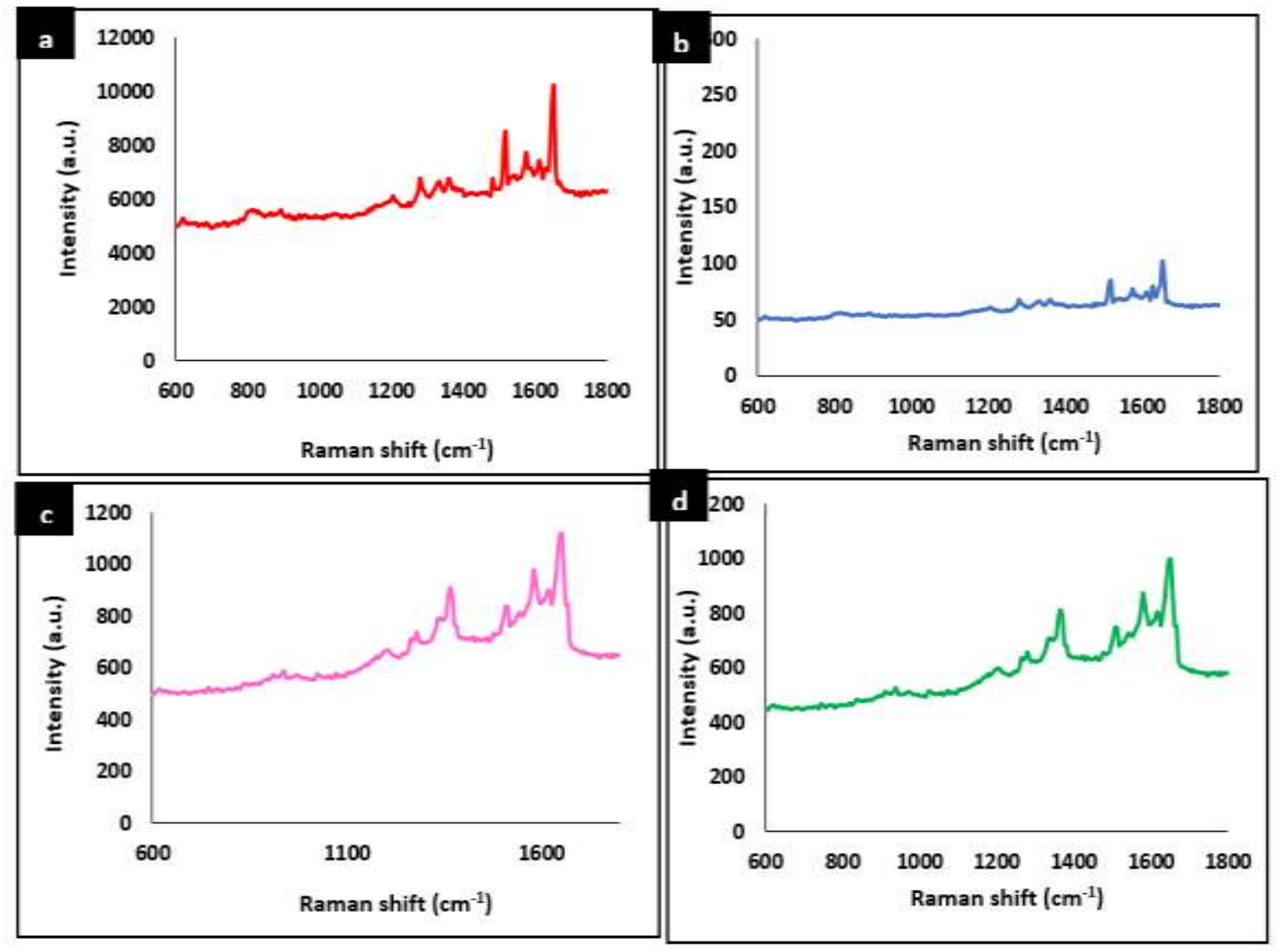

Figure 6-SERS spectra of Au-NPs and Ag-NPs: (a and c) as-prepared, (b and d) after 6 months.

\section{Conclusion}

The drop casting process of plasmonic nanoparticles on glass substrates resulted in an inexpensive and easy to perform SERS sensor. The influences of different types of plasmonic nanoparticles (AuNPs and Ag-NPs) as well as that of aging on the performance of SERS sensors were studied. We show that the Raman spectra of Au-NPs and Ag-NPs/glass sensors for R6G detection were efficiently improved. Furthermore, the specific surface area of Au-NPs and Ag-NPs as well their sizes and the aging process play significant roles on the performance of their glass SERS sensors. The SERS performance of the of Au-NPs and Ag-NPs/glass was assessed for a very low concentration, $10^{-10} \mathrm{M}$, of R6G dye. The Raman signal was strongly enhanced by our SERS substrate. The performance of the 
as-prepared SERS sensors was better than that of the Au-NPs. The aged Au-NPs SERS sensors were of much higher efficiency than those based on Ag-NPs.

\section{References}

1. Hamouda, I. 2012. "Current perspectives of nanoparticles in medical and dental biomaterials." Journal of biomedical research, 26(3): 143-151.

2. Albrecht, M., Janke, V., Sievers, S., Siegner, U., Schüler, D. and Heyen. U. 2005. "Scanning force microspy study of biogenic nanoparticles for medical applications." Journal of magnetism and magnetic materials, 290: 269-271.

3. Rai, M., Alka Y. and Aniket G. 2009. "Silver nanoparticles as a new generation of antimicrobials." Biotechnology advances, 27(1): 76-83.

4. Piao, Mei Jing, Kyoung Ah Kang, In Kyung Lee, Hye Sun Kim, Suhkmann Kim, Jeong Yun Choi, Jinhee Choi, and Jin Won Hyun. 2011. "Silver nanoparticles induce oxidative cell damage in human liver cells through inhibition of reduced glutathione and induction of mitochondriainvolved apoptosis." Toxicology letters, 201(1): 92-100.

5. Chen, X. and Hermann J. 2008. Schluesener. "Nanosilver: a nanoproduct in medical application." Toxicology letters, 176(1): 1-12.

6. Al-Batat, H., Alwan M. and Ahmed K. 2012. "The effect of the etching time on the electrical properties of nano structure silicon." Iraqi Journal of Physics, 10(18): 1-4.

7. D’Souza, Lawrence, and Ryan R. 2016. "Synthesis of metal colloids." In Catalyst Preparation, pp. 107-152. CRC Press.

8. Yang, Guowei, ed. 2012. Laser ablation in liquids: principles and applications in the preparation of nanomaterials. CRC Press.

9. Chang, Chun-Ch., Kuang-Hsuan Y., Yu-Chuan L. and Ting-Chu H. 2012. "New pathway to prepare gold nanoparticles and their applications in catalysis and surface-enhanced Raman scattering." Colloids and Surfaces B: Biointerfaces, 93: 169-173.

10. Alwan, M., Rasha B. and Amer B. 2018. "Morphological and Electrical Properties of gold nanoparticles/macroPorous Silicon for CO2 Gas." Iraqi Journal of Science: 57-66.

11. Wali, Layla A., Alwan M. Alwan, Amer B. Dheyab, and Duaa A. 2019. "Excellent fabrication of $\mathrm{Pd}-\mathrm{Ag}$ NPs/PSi photocatalyst based on bimetallic nanoparticles for improving methylene blue photocatalytic degradation." Optik, 179: 708-717.

12. Alwan, Alwan M., Intisar A. Naseef, and Amer B. 2018. "Well controlling of plasmonic features of gold nanoparticles on macro porous silicon substrate by $\mathrm{HF}$ acid concentration. " Plasmonic, 13(6): 2037-2045.

13. Jabbar, Allaa A., Alwan M. Alwan, Mehdi Q. Zayer, and Azhar J. 2020. "Efficient single cell monitoring of pathogenic bacteria using bimetallic nanostructures embedded in gradient porous silicon." Materials Chemistry and Physics, 241: 122359.

14. Primera-Pedrozo, Oliva M., Gabriela Del Mar Rodríguez, Jorge Castellanos, Hilsamar FelixRivera, Oscar Resto, and Samuel P. Hernández-Rivera. 2012. "Increasing surface enhanced Raman spectroscopy effect of RNA and DNA components by changing the $\mathrm{pH}$ of silver colloidal suspensions." Spectrochimica Acta Part A: Molecular and Biomolecular Spectroscopy, 87: 77-85.

15. Hou, Xiaomiao, Xiaoling Zhang, Shutang Chen, Yan Fang, Na Li, Xiaoman Zhai, and Yu Liu. 2011."Size-controlled synthesis of Au nanoparticles and nanowires and their application as SERS substrates." Colloids and Surfaces A: Physicochemical and Engineering Aspects, 384(1-3): 345351.

16. Kundu, Subrata, Madhuri Mandal, Sujit Kumar Ghosh, and Tarasankar Pal. 2004. "Photochemical deposition of SERS active silver nanoparticles on silica gel and their application as catalysts for the reduction of aromatic nitro compounds." Journal of colloid and interface science, 272(1): 134144.

17. Photopoulos, P., Boukos, N., Panagopoulou, M., Meintanis, N., Pantiskos, N., Raptis, Y. and Tsoukalas, D. 2011. "Size control of Ag nanoparticles for SERS sensing applications." Procedia Engineering, 25: 280-283.

18. Vlckova, B., Pavel, I., Sladkova, M., Siskova, K. and Slouf, M. 2007. "Single molecule SERS: Perspectives of analytical applications." Journal of molecular structure, 834: 42-47. 
19. Primera-Pedrozo, Oliva M., Jackeline I. Jerez-Rozo, Edwin De La Cruz-Montoya, Tatiana LunaPineda, Leonardo C. Pacheco-Londono, and Samuel P. Hernandez-Rivera. 2008. "Nanotechnology-based detection of explosives and biological agents simulants." IEEE Sensors Journal, 8(6): 963-973.

20. Alwan, M., Raad A. and Shahad M. 2019. "Well-Controlled Generation Process of Bimetallic $\mathrm{Ag} / / \mathrm{Au}$ Colloidal Nanoparticles by Non-Thermal Plasma DC Glow Discharge." Iraqi Journal of Science, 1274-1285.

21. Alwan M., Wali, A. and Ali A. 2018. "Optimization of AgNPs/mesoPS active substrates for ultralow molecule detection process." Silicon, 10(5): 2241-2251.

22. Wali, A., Khulood K. and Alwan M. 2019. "Rapid and highly efficient detection of ultra-low concentration of penicillin $\mathrm{G}$ by gold nanoparticles/porous silicon SERS active substrate." Spectrochimica Acta Part A: Molecular and Biomolecular Spectroscopy, 206: 31-36.

23. Hashim, Duaa A., Alwan M. Alwan Muslim F. and Jawad, F. 2018. "Influence of Ag NPs on Silicon Nanocolumns NH3 Gas Sensors." Journal of The Electrochemical Society, 165(14): B773B778. 